\title{
Building an eco-surplus culture is a possible solution for curbing environmental problems
}

Minh-Hoang Nguyen

Ritsumeikan Asia Pacific University

Beppu, Oita 874-8577, Japan

November 23, 2021

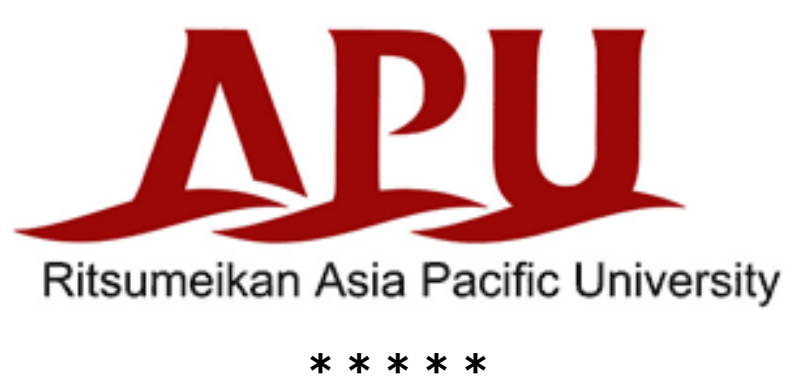

The age that we are living in is called Anthropocene because of the tremendous impacts of human activities on the synergetic dynamics of climatological, geological and biological processes on Earth. The impacts are so severe that the climate breakdown will pass the point of no return without aggressive actions taken [1].

However, as Boonstra [2] stipulated, novel solutions should be embraced and encouraged.

"Recipes of smarter technology, global institutions, and more adaptive management have so far not closed the gap between knowing and causing the Anthropocene. It is time for something else. An anthroposphere with less stuff and less billionaires by redressing its scale deserves wider attention as possible solution for human wellbeing on Earth."

I agree and think that one possible solution is to build eco-surplus culture and reduce eco-deficit culture simultaneously. Vuong [3] came up with this idea because humans are the main contributor to the crisis, so changing their norms and behaviors is necessary to tackle environmental problems.

Although the solution is available, it also needs to be heard in order to generate impacts. Perhaps, it is time that science has to be made less monopolized [4]. 


\section{References}

1. Tollefson J. (2021). IPCC climate report: Earth is warmer than it's been in 125,000 years. Nature, 596, 171-172.

2. Boonstra WJ. (2021). Closing the gap between knowing and causing the Anthropocene. Ambio, 50, 1767-1773.

3. Vuong QH. (2021). The semiconducting principle of monetary and environmental values exchange. Economics and Business Letters, 9 (3), 284-290.

4. Vuong QH. (2021). Western monopoly of climate science is creating an eco-deficit culture. Economy, Land \& Climate Insight. Retrieved from: https://elcinsight.org/western-monopoly-of-climate-science-is-creating-an-eco-deficitculture/ 